\title{
A Cyber-Physical Approach to the Management and Control of Manufacturing Systems
}

\author{
Elvis Hozdić*1 - Dominik Kozjek ${ }^{1}$ - Peter Butala ${ }^{1,2}$ \\ 1 University of Ljubljana, Faculty of Mechanical Engineering, Slovenia \\ 2 Tshwane University of Technology, Department of Industrial Engineering, South Africa
}

\begin{abstract}
Cyber-physical systems (CPSs) open up new perspectives for the design, development, implementation, and operation of manufacturing systems and will enable a paradigm shift in manufacturing. The objective of this research is to develop a new concept of cyber-physical production systems (CPPSs) and, on this basis, to address the issue of management and control, which is crucial for the effective and efficient operation of manufacturing systems. A new model of CPPS is proposed. The model integrates digitalized production planning, scheduling, and control functions with a physical part of manufacturing system and enables the self-organization of the elements in production. A case study demonstrates feasibility of the approach through the use of simulation experiments, which are based on real industrial data collected from a company that produces industrial and energy equipment.

Keywords: cyber-physical production system, production planning and control, self-organization

Highlights

- A conceptual model of cyber-physical production systems (CPPSs) is developed.

- A cyber-physical approach to the production planning and control (PPC) of manufacturing systems is presented.

- $\quad$ The presented approach to the production planning, scheduling and the self-organization in the CPPS is demonstrated through the use of simulation experiments.
\end{abstract}

\section{INTRODUCTION}

A new production philosophy that has recently emerged under the name of Industry 4.0 opens up a space for novel approaches to industrial production. Industry 4.0 is a new way of organizing and controlling complete value-adding systems [1]. Industry 4.0 (I4.0) is driven by new scientific discoveries, enriched knowledge, new and better materials, and new technologies, especially in the field of information and communication technologies (ICT). In addition, novel organizational forms and the innovative managerial principles of emergence, selforganization, learning, open innovation, collaboration, and the networking of humans and organizations will become the key elements of the next generation of manufacturing systems.

Modern manufacturing enterprises must be focused on agile, networked, service-oriented, green, and social manufacturing practices, among others [2]. However, in order to develop and implement these practices, a transformation of manufacturing systems from the traditionally isolated, hierarchical structures into open and distributed networked structures is needed. The foundations of this transformation are the three key enablers of I4.0: connectivity, digitalization and cybernation. One of the novel concepts arising from I4.0 is the so-called cyber-physical systems (CPSs).
The CPS integrates computational and physical processes. In a CPS, embedded computers and networks monitor and control the physical processes, usually with feedback loops in which physical processes affect the computations and vice versa [3]. On this basis, cyber-physical production systems (CPPS) are also defined [4] to [11].

In a CPPS the horizontal integration is accomplished through value networks, and the vertical integration is achieved through networked manufacturing systems [6].

The emergence of CPSs and cross-linked CPPSs will lead to a fundamental restructuring of manufacturing work and logistic systems, and will require new forms of human-machine interaction [12]. Furthermore, innovative methods for the management and control of CPPSs based on logistics models will improve the processing of customers' orders [13].

An important part of the management and control of manufacturing systems, which allows them to cope with this challenge, are the functions of production planning and control (PPC) [14]. Several emerging approaches to the management and control of traditional manufacturing systems are presented in [15] to [18].

Unlike with traditional approaches, a CPPS will enable the decomposition of a user's request into several tasks and assign them to distributed heterogeneous features in a parallel- computing 
environment [19]. In this context, self-organization could be a viable alternative for solving the dynamic scheduling problem [20].

Several emerging approaches to the management and control of CPPS are presented in [12], [13] and [21] to [25].

The current research in the field of the management and control of CPPSs offers innovative approaches, but they are not yet implemented in industrial environments. An appropriate methodology that would integrate different levels of decision making in a manufacturing enterprise and which would enable the responsive and adaptive management and control of manufacturing systems in real time is still absent.

This research addresses the question of how the CPPS concept can contribute to the improved management, planning, scheduling, control and monitoring of manufacturing systems. It is expected that within CPPSs these functions will be reinforced through connectivity, digitalization and cybernation at different levels of the decision-making in an enterprise. This will enable the management and control of manufacturing systems in real-time.

The paper proposes a novel CPPS model and introduces a new method for the management and control of CPPSs in real time. Furthermore, generic cybernetic, and functional models for deploying PPC functions within CPPSs are presented.

The remainder of the paper is organized as follows. In Section 1, the new conceptual model of CPPS is introduced. In Section 2, the cyber-physical approach to the management and control of CPPSs is proposed. In Section 3, the use of the approach is illustrated with a case study based on industrial data. Section 4 summarizes the work carried out and provides suggestions for future research.

\section{MODEL OF CYBER-PHYSICAL PRODUCTION SYSTEMS} (CPPSs)

The objective of this research is to develop a new concept of CPPSs and, on this basis, to address the issue of management and control, which is crucial for the effective and efficient operations of the manufacturing systems. The development originates from previous work on basic manufacturing structures such as elementary work systems (EWS) [26], autonomous work systems (AWS) [27], complex adaptive manufacturing systems (CAMS) [26], and adaptive distributed manufacturing systems (ADMSs) [27]. These structures symbolized in terms of cybernetic models, represent a sound basis for their upgrading into appropriate CPPS models.
The question here is how to implement the mentioned three key I4.0 enablers, i.e., connectivity, digitalization and cybernation in the existing EWS, AWS, CAMS and ADMS models of manufacturing systems in order to realize the concept of cyberphysical production systems at all levels and thus to enable the seamless connectivity among all the elements and systems, and the transmission of information and decision making in real time. In the next section the transformation of EWS, AWS, CAMS and ADMS into appropriate CPS models is elaborated.

\subsection{CPPS Conceptual Model}

The generic conceptual model of a CPPS is shown in Fig. 1.

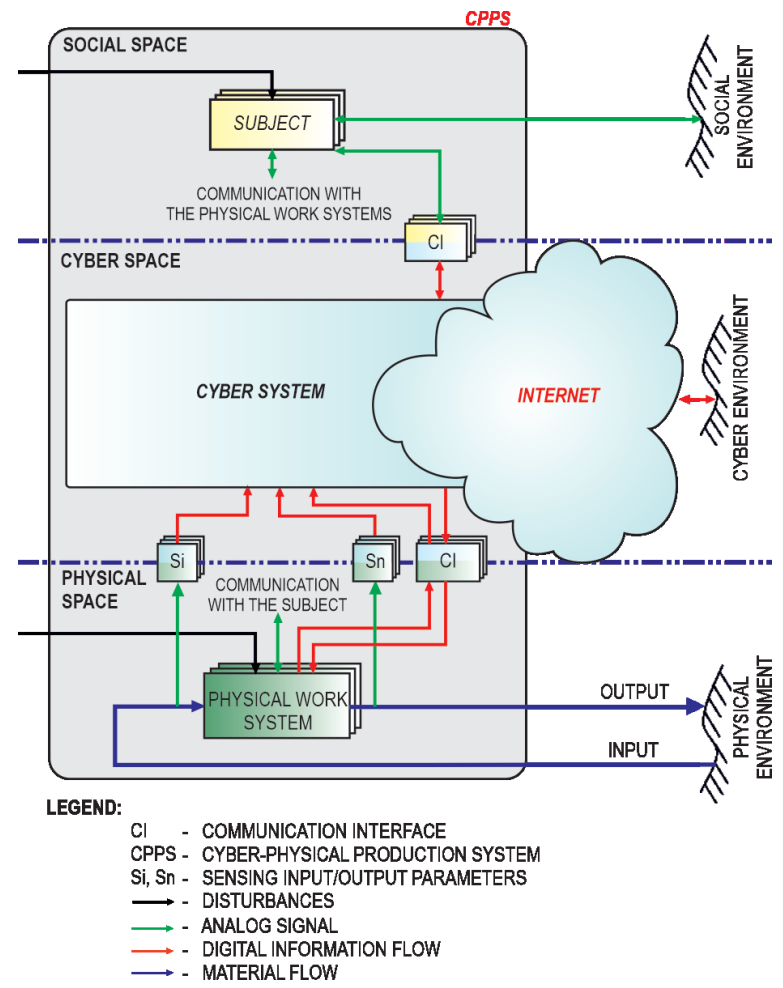

Fig. 1. Generic model of a CPPS

The model consists of three elements: (1) the human Subject as a social element, (2) the cyber system (CS) as a cyber element, and (3) the physical work system (PWS) as a physical element. Each of the elements exists in its own space: the Subject in the social space, the CS in the cyber space and the PWS in the physical space. The connectivity between these elements and thus between the different spaces is enabled via the corresponding communication interfaces, which also bridge the different spaces. 
Each element has the corresponding relations with its specific environment: the Subject with the business and social environment, the CS with the cyber environment and the PWS with the physical environment. The PWS structure is based on the EWS structure [26].

The important distinction between the EWS and the PWS is that in the latter the Subject is moved from the physical space to the social space of the CPPS. The new element of the model is the cyber system (CS), which is incorporated into the cyber space, Fig. 1. The CS of the CPPS can be structured into three hierarchical levels: 1) operational level, 2) coordination \& collaboration level, and 3) business level, Fig. 2. Thus, it represents a CPS version of the CAMS (factory).

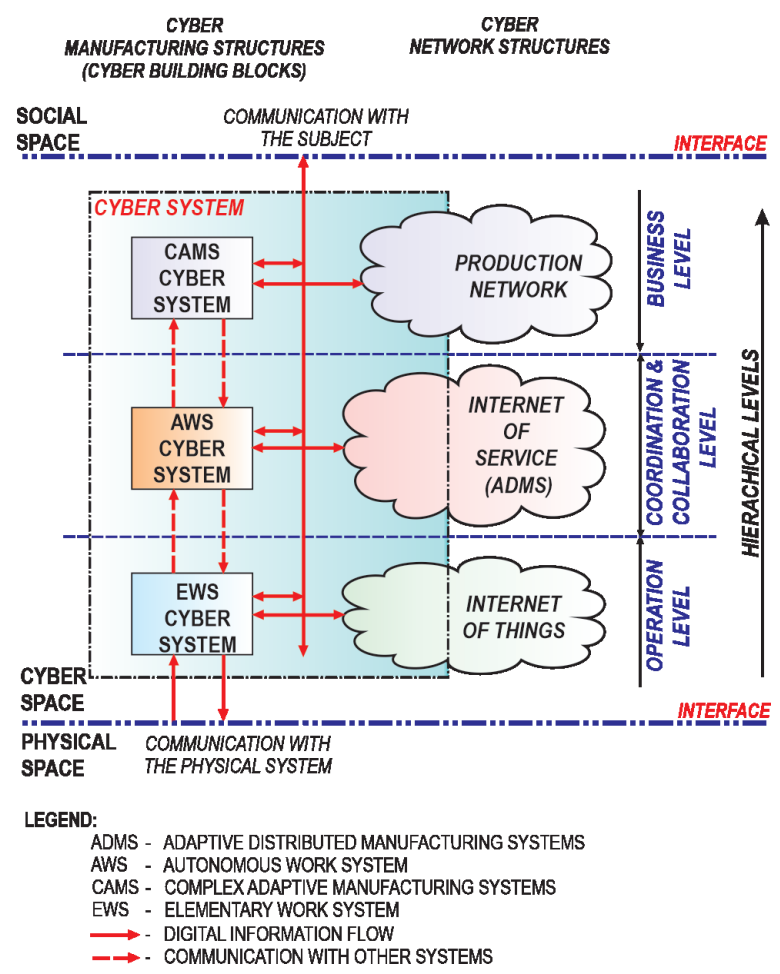

Fig. 2. Structure of the cyber systems of the CPPS

The infrastructure of the CS enables vertical connectivity between the cyber manufacturing structures (EWS cyber system, AWS cyber system and CAMS cyber system) and the horizontal connectivity of the cyber manufacturing structures in the network structures (Internet of Things, Internet of Services (ADMS), and the production network).

The EWS cyber system enables 1) connecting the physical and social spaces in the EWS, 2) digitalization of the functions (e.g., monitoring and control) and the cybernation and work processes in the EWS, 3) development and implementation of new digitalized functions in the EWS (e.g., selforganization, self-adaption, self-diagnostic, selflearning, etc.), 4) vertical connection of the EWS in the integrated work structure (AWS, CAMS, ADMS, production networks), and 5) horizontal connection of the EWS in a network within the Internet of Things, Fig. 2. The EWS cyber system structure is shown in Fig. 3.

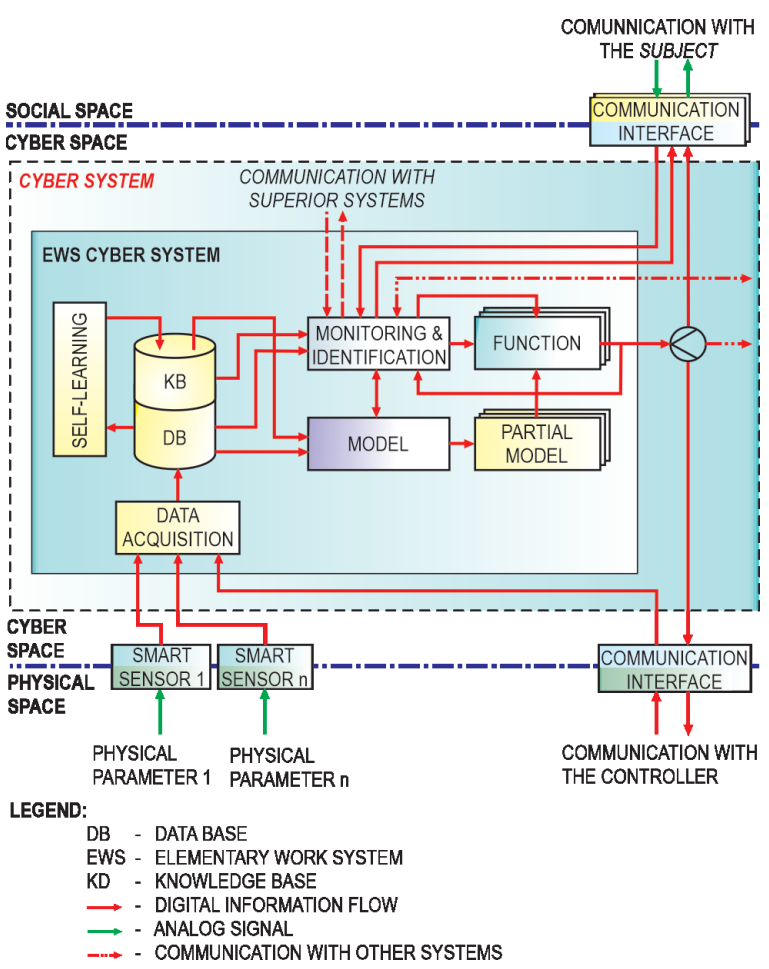

Fig. 3. Structure of the EWS cyber system

The new function of self-organization in the EWS cyber system is presented in more detail in Section 2, through a description of the cyber-physical approach to the management and control of the CPPS.

The AWS cyber system enables 1) vertical connection with subordinated EWS cyber systems, as well as with superior cyber systems, 2) implementation of the digitalized autonomous function in the AWS (management of resources, scheduling, quality control, performance measurements, prognostics, selflearning, etc.), and 3) horizontal connection of the AWS and ADMS within the Internet of Services.

The AWS cyber system is connected with the superior system (the CAMS cyber system) through the coordination function, while it is connected to the subordinate systems (the EWS cyber systems) through the monitoring and control functions, as shown in Fig. 2. The AWS cyber system structure is shown in Fig. 4. 


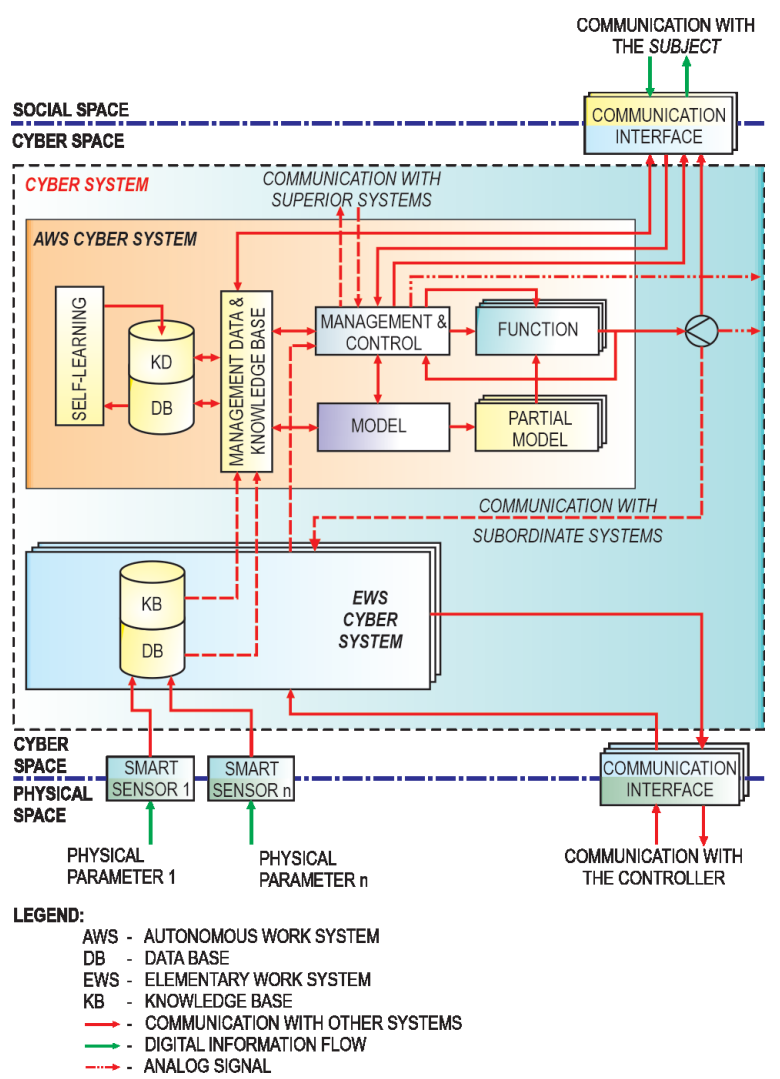

Fig. 4. Structure of the AWS cyber system

The digitalized function of scheduling in the AWS cyber system is presented in Section 2 and validated in Section 3 through a simulation experiment.

The CAMS cyber system, as show in Fig. 2, enables 1) horizontal connection of the CPPS in a production network or other networked forms, 2) vertical connection with subordinated AWS cyber systems and EWS cyber system, and 3) implementation of functions such as sales, marketing, purchasing, project management, design, production planning, quality assurance, etc. The CAMS cyber system structure is shown in Fig. 5.

In Section 2 the management and control of CPPSs with particular emphasis on the production planning and control is described in more detail.

\section{MANAGEMENT AND CONTROL OF CPPSS}

The managing of manufacturing systems such as factories is, due to their ever-increasing complexity, a very demanding function. It affects all the actors in the system and decisively influences the system's performance. For this reason, the digitalization and cybernation of the function could have various beneficial aspects.

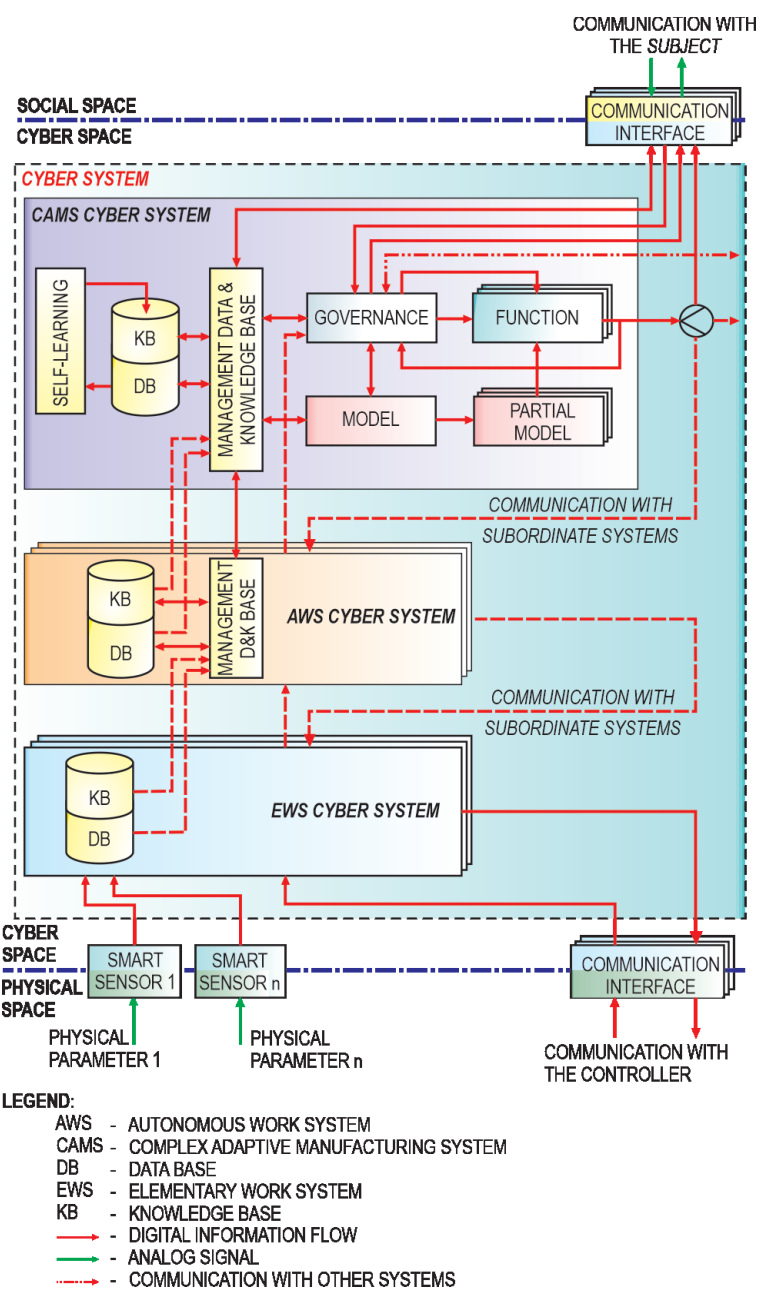

Fig. 5. Structure of the CAMS cyber system

An important part of the management function in a manufacturing system is related to PPC. The major issue with PPC is how to achieve the on-time delivery of products and services in accordance with customers' orders using the available resources and within the anticipated costs.

The PPC function is performed at all three levels of the manufacturing system. Hence, it is a comprehensive domain for researching cyber-physical concepts in manufacturing systems.

\subsection{Production Planning and Control in CPPSs}

The application of the CPPS concept in the PPC domain is outlined next. The overall concept of PPC in the CPPS is illustrated in Fig. 6.

Fig. 6 shows a functional diagram of the activities related to PPC. These activities are spread over all three levels of the manufacturing system: from the business level down to the execution level. This gives 


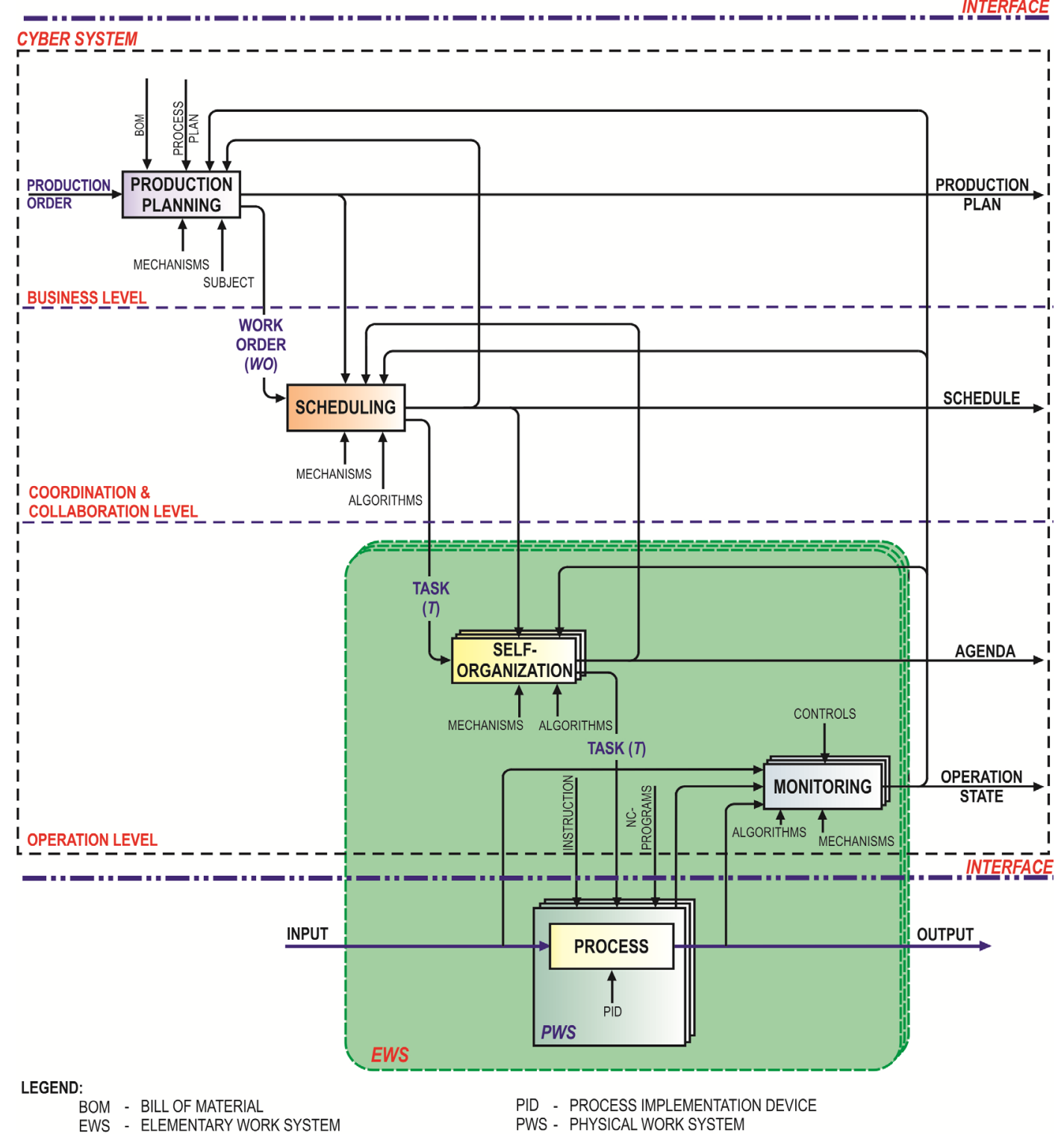

Fig. 6. Functional diagram of management and control in a cyber system

us the opportunity to elaborate how the CPPS concept can be implemented by connecting the cybernated functions from different levels of the manufacturing system in series and/or in parallel within the cyber system, as well as how to connect them with the physical system.

As can be seen in Fig. 6, the core of the PPC system is located in the cyber system. This implies the digitalization and cybernation of the PPC functions.

Besides the traditional PPC functions, i.e., production planning, scheduling and monitoring, an enhanced control function is introduced at the operation level; it is called self-organization. The role of this function is to allow the EWSs to arrange their own agendas for tasks by themselves. This function is introduced in the next.

The Self-organization activity is a part of the EWS cyber system. It enables the EWS to make autonomous decisions about its work planning and organization. The self-organization function is activated for each new event (delay in performing tasks, arrival of a new task, system fault, etc.).

The output of the self-organization is the list of the tasks in the form of an agenda. The agenda is the set of the self-organized tasks for the individual EWS. 
The agenda of the EWS is a sequence of allocated tasks.

The time of the new event, $t_{N E}$, is defined with the new events, a new look into the state, and similar. The new events are the completion of a task, the arrival of a new task, the delay of the tasks, etc.

The task schedule in a single agenda defines the various heuristic scheduling algorithms such as first-in-first-out (FIFO), earliest-due-date (EDD), weighted-shortest-processing-time (WSPT), shortest processing time (SPT), largest number of successors (LNS), and similar.

The dynamic production environment in which the PWS exists is continually influenced by the EWS's individual agenda and requires it to be constantly refreshed in real time. The CPPS concept enables the adaptation of the agenda in different real-time conditions by defining various alternative agendas for a particular EWS.

Which agenda, i.e., which variants of the heuristic scheduling algorithms will be used, depends on the evaluation function of the agenda. The agendaevaluation function is based on the performance measures of an assessment. The basic performance measures of an assessment an agenda include the parameters of the tasks depending on the execution times and the deadlines (start times, finish times, completion duration time, delay, tardiness, earliness, due date, etc.).

The implementation of a cybernated PPC can be realized using different mechanisms, such as for example multi-agent system (MAS).

The presented approach of the production planning, scheduling and the self-organization in the CPPS is demonstrated in the following case study.

\section{CASE STUDY}

The case-study experiments are based on real manufacturing data sourced from a typical engineerto-order (ETO) company that produces industrial and energy equipment, such as turbines, pumps, valves and gates, cranes, and other products and solutions.

ETO manufacturing is typically a projectoriented type of manufacturing. For the development, a project is structured according to the principle of work breakdown into smaller components, i.e., parts, modules, sub-assemblies, or higher-level tasks. For each of these components there is one or more work orders, and each work order defines a set of tasks, or in the case of production, a sequence of tasks that must be executed on different work stations.

In the observed company it is typical for several dozen projects and approximately one thousand work orders to be in the process at any given moment. The proposed CPS approach will be used to manage both the large-scale and dimensionality of the problem related to the management of work orders and the tasks on the shop floor.

A production-scenario simulation tool, presented in [28], is used during the experiments. The simulation tool is based on pre-processed Manufacturing Execution System (MES) data (Table 1). Source MES data is a backup of the observed ETO company's MES database for a period of 18 months.

The aforementioned tool simulates how work orders pass across the shop floor by knowing the work orders' sequences of tasks, the work orders' start times, the processing times of the tasks, the corresponding EWS of each task, etc. A start time for a work order is determined as the actual start time of

Table 1. Structure of the pre-processed MES data

\begin{tabular}{|c|c|c|c|c|}
\hline Entity & Symbol & Attributes & Symbol & No. of records \\
\hline \multirow{6}{*}{ Task } & \multirow{6}{*}{$T$} & Task-identification number & $T_{I D}$ & \multirow{6}{*}{58865} \\
\hline & & Elementary work system-identification number & $E W S_{I D}$ & \\
\hline & & Planned start time & $t_{T S P L}$ & \\
\hline & & Actual processing time & $t_{T P A C}$ & \\
\hline & & Corresponding work order-identification number & $\left(W 0_{I D}\right)$ & \\
\hline & & Corresponding WBS code & $W B S_{\text {code }}$ & \\
\hline \multirow{5}{*}{ Work order } & \multirow{5}{*}{$W 0$} & Work order-identification number & $W 0_{I D}$ & \multirow{5}{*}{14421} \\
\hline & & Actual start time (date and time) & $t_{W 0 A C}$ & \\
\hline & & Planned start time (date) & $t_{W O S P L}$ & \\
\hline & & Planned completion time (due date) & $t F_{W O D D}$ & \\
\hline & & Sequence of tasks (ordered list of tasks) & $T L$ & \\
\hline \multirow{2}{*}{ Elementary work system } & \multirow{2}{*}{$E \boldsymbol{W S}$} & Elementary work system-identification number & $E W S_{I D}$ & \multirow{2}{*}{352} \\
\hline & & List of similar work systems & $E W S_{L}$ & \\
\hline
\end{tabular}


the first corresponding task, and the sequence of tasks for an individual work order is determined by the sequence of the tasks' actual start times.

The simulation tool makes it possible to test different heuristic algorithms for the scheduling tasks. In the following experiments this functionality will be used to demonstrate the usability and the effects of the proposed approach.

The three different heuristic algorithms for the scheduling tasks are tested in the experiments: 1) FIFO, 2) EPT, and 3) EPT\&WSO.

FIFO: when several tasks are waiting to be processed in some work system, the selected task that will be the first to be processed in that work system is the task with the longest waiting time.

EPT: the selected task that will be the first processed is the task with the earliest planned start time.

EPT\&WSO: the earliest-planned-time and the current occupancy of the work systems for which the current work orders will be processed after they pass the observed work system are integrated. Among all the tasks in the observed work system, the task that has the largest value of the indicate function $(G)$, Eq. (1), is selected to be the first processed at that work system, where $\alpha$ is the normalized delay of the observed task and $\beta$ is the normalized average number of tasks in the following EWSs of the work order to which corresponds the observed task $\boldsymbol{T}$, and $w_{\alpha}$ and $w_{\beta}$ are the weights.

$$
G=\frac{\left(w_{\alpha} \cdot \alpha+w_{\beta} \cdot \beta\right)}{\left(w_{\alpha}+w_{\beta}\right)} .
$$

A normalized delay $\alpha$ for the observed task is defined in Eq. (2), where $d(\boldsymbol{T})$ is the start delay of the task in the agenda; $d_{\min }^{*}$ and $d_{\max }^{*}$ are the minimum and maximum values of $d(\boldsymbol{T})$ among all the tasks in the observed EWS from the past. In the implementation of the EPT\&WSO algorithm used for the experiments of this study, when searching for the $d_{\min }^{*}$ and $d_{\max }^{*}$ values, the most extreme values are ignored.

$$
\alpha=\frac{d(\boldsymbol{T})-d_{\min }^{*}}{\left(d_{\max }^{*}-d_{\min }^{*}\right)} .
$$

A weight $w_{\alpha}$ Eq. (3) is defined with the maximum value of $d_{\max }$, which is the maximum value of $d(\boldsymbol{T})$ among all the current tasks in the observed EWS, where $L_{\alpha}$ is the limit value of the delay and it is determined on the basis of the experience and characteristics of the observed production system. The practical purpose of this weight is the following: if there is a task with a shorter time reserve in the set of tasks, then the start delays of the task should be taken into account with increased weight when generating the agenda. For the experiments of this study, $\delta$ was set to 0.1 and $L_{\alpha}$ was set to -30 days.

$$
w_{\alpha}=\left\{\begin{array}{ll}
1 ; & d_{\max } \geq L_{\alpha} \\
\delta ; & d_{\max }<L_{\alpha}
\end{array} .\right.
$$

The normalized average number of tasks in the following EWS of the observed work order $\beta$ is defined in Eq. (4), where $m_{j}$ is the number of waiting tasks in the EWS of the $j^{\text {th }}$ task after the observed task in the work order's sequence to which corresponds the observed task; $m_{\max }$ is the maximum number of waiting tasks among all the EWSs from the past; and $\mathcal{M}$ is the number of subsequent tasks that follow the currently observed task in the corresponding work order's sequence of tasks.

$$
\beta=\frac{-\sum_{j=1}^{\mathcal{M}} \frac{m_{j}}{m_{\max }}}{\mathcal{M}} .
$$

A weight $w_{\beta}$ is defined in Eq. (5), where $L_{\beta}$ is the limit that defines the critical delay of tasks (a delay with a value that is greater than $L_{\beta}$ is a critical delay), $t_{N E}$ is the time of the new event, and $t_{\beta}$ is the time from which further EWSs' occupation is taken into account when generating the agendas (after the start of the simulation, it will take some time to include EWSs' occupation method of selecting the operation). For the experiments of this study, $L_{\beta}$ was set to 0 days and $t_{\beta}$ was set to approximately 3 months after the simulation start time.

$$
w_{\beta}=\left\{\begin{array}{l}
0 ; t_{N E}<t_{\beta} \\
1 ; d_{\max } \leq L_{\beta} \wedge t_{N E} \geq t_{\beta} . \\
\delta ; d_{\max }>L_{\beta} \wedge t_{N E} \geq t_{\beta}
\end{array}\right.
$$

To demonstrate the effects of using different scheduling algorithms in different scenarios, the elementary work system EWS $_{351}$ was analyzed in the simulation process. The simulation time (the time of the event, $t_{N E}$ ) was chosen on 2010-03-29 at 13:39:06 (until this time the FIFO algorithm was used). At that moment, the $\mathrm{EWS}_{351}$ had just finished a task, and in $\mathrm{EWS}_{351}$ three other tasks were waiting to be processed. The simulation result for the case of using the FIFO algorithm is shown in Table 2.

The scenario presented in Table 2 is based on the waiting time of the task $t_{T W}$. This makes it possible to first accomplish task $\boldsymbol{T}_{\mathbf{1}}$, which has the longest waiting time $t_{T_{1} W}=0: 58: 29$ in the list of tasks for $\mathrm{EWS}_{351}$.

In Table 3 the result for the case of using the EPT algorithm is presented. The EPT alternative agenda 
makes possible the first task $\boldsymbol{T}_{\mathbf{3}}$ with the earliest planned start time $t_{T_{3} S P L}=2010-04-02$, followed by the $T_{1}$ and $T_{2}$, which has a later planned start time $t_{T_{1} S P L}=2010-04-06$.

Table 2. FIFO alternative agenda for $E S_{351}$

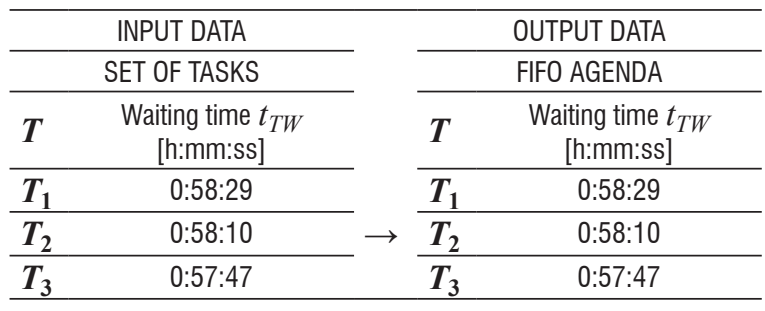

Table 3. EPT alternative agenda for $E \mathrm{~S}_{351}$

\begin{tabular}{|c|c|c|c|c|}
\hline \multicolumn{3}{|c|}{ INPUT DATA } & \multicolumn{2}{|r|}{ OUTPUT DATA } \\
\hline & SET OF TASKS & & & EPT AGENDA \\
\hline$T$ & $\begin{array}{l}\text { Planned start time } t_{T S P L} \\
\text { [yyyy-mm-dd] }\end{array}$ & & $T$ & $\begin{array}{c}\text { Planned start time } t_{T S P L} \\
\text { [yyyy-mm-dd] }\end{array}$ \\
\hline$T_{1}$ & 2010-04-06 & & $T_{3}$ & $2010-04-02$ \\
\hline$T_{2}$ & $2010-04-06$ & $\rightarrow$ & $T_{1}$ & $2010-04-06$ \\
\hline$T_{3}$ & 2010-04-02 & & $T_{2}$ & $2010-04-06$ \\
\hline
\end{tabular}

The simulation result for the case of using the EPT\&WSO algorithm is presented in Table 4. The task $\boldsymbol{T}_{\mathbf{1}}$ has the highest value of the indicated function $G=0.453$, meaning that this task would, in this case, be the first processed in the $\mathrm{EWS}_{351}$.

Table 4. EPT \& WSO alternative agenda for $E W S_{351}$

\begin{tabular}{|c|c|c|c|c|}
\hline \multicolumn{2}{|r|}{ INPUT DATA } & & \multicolumn{2}{|r|}{ OUTPUT DATA } \\
\hline & SET OF TASKS & & & EPT AGENDA \\
\hline$T$ & $\begin{array}{l}\text { Planned start time \& } \\
\qquad G\end{array}$ & & $T$ & $\begin{array}{c}\text { Planned start time \& } \\
G G\end{array}$ \\
\hline$T_{1}$ & $\begin{array}{c}2010-04-06 \\
0.453\end{array}$ & & $T_{1}$ & $\begin{array}{l}2010-04-06 \\
0.453\end{array}$ \\
\hline$T_{2}$ & $\begin{array}{c}2010-04-06 \\
0.362\end{array}$ & $\rightarrow$ & $T_{3}$ & $\begin{array}{l}2010-04-02 \\
0.409\end{array}$ \\
\hline$T_{3}$ & $\begin{array}{l}2010-04-02 \\
0.409\end{array}$ & & $T_{2}$ & $\begin{array}{c}2010-04-06 \\
0.362\end{array}$ \\
\hline
\end{tabular}

The results of the agent deployment in the CPPS concept refer only to the observed EWS $_{351}$. Thus, the possibility of self-organization within $\mathrm{EWS}_{351}$ is demonstrated under the influence of various factors affecting the EWS observed and coming from the realization of the task in the previous EWS or the EWS to further realize the work order that the observed task belongs to.

In the second part of the experiments, each scheduling algorithm is tested in a separate simulation run, for which the output is a resulting production scenario. On this basis, three scenarios are established.

Scenario S1: The self-organization function updates the agenda of a corresponding EWS on the basis of FIFO heuristic algorithm.

Scenario S2: The self-organization function updates the agenda of a corresponding EWS on the basis of EPT heuristic algorithm.

Scenario S3: The self-organization function updates the agenda of a corresponding EWS on the basis of EPT\&WSO algorithm.

For the performance analysis of the whole production system from the point of view of applying different scheduling algorithms, the following simulation settings are used in the experiments: the simulation start time is set to 2010-01-04 and the simulation end time to 2011-07-01, meaning that the production is simulated for a period of approximately 18 months.

To measure the effect on the production performance, four performance measures are selected: 1) the distribution of work- order delay times. Generally, the objective is that a work order does not end too late, nor very early; 2) the average work-order delay times influences the average work-order lead times.

The objective is that the work-order lead times are short; 3) the average waiting time for a work order before it is processed at the EWS. The objective is that this time is as short as possible, and 4) the average number of waiting work orders (or tasks) in the EWS. The results of the simulation are presented in Table 5 and Fig. 7.

Table 5. Results of the simulation for the set time from 2010-01-04 to 2011-07-01

\begin{tabular}{lccccc}
\hline Heuristic & $\begin{array}{c}\text { Average } \\
\text { W0 } \\
\text { delay time } \\
\text { [day] }\end{array}$ & $\begin{array}{c}\text { W0 } \\
\text { number } \\
\text { with a } \\
\text { positive } \\
\text { delay value }\end{array}$ & $\begin{array}{c}\text { W0 } \\
\text { number } \\
\text { with a } \\
\text { negative } \\
\text { delay value }\end{array}$ & $\begin{array}{c}\text { Average } \\
\text { waiting } \\
\text { time at } \\
\text { EWS } \\
\text { [s] }\end{array}$ & $\begin{array}{c}\text { Average } \\
\text { number } \\
\text { of } \\
\text { waiting } \\
\text { W0 }\end{array}$ \\
\hline $\begin{array}{l}\text { Scenario } \\
\text { S1 }\end{array}$ & -36.61 & 7056 & 7283 & 551379 & 11.01 \\
\hline $\begin{array}{l}\text { Scenario } \\
\text { S2 }\end{array}$ & -33.66 & 6609 & 7730 & 586916 & 4.56 \\
\hline $\begin{array}{l}\text { Scenario } \\
\text { S3 }\end{array}$ & -34.66 & 6716 & 7623 & 564221 & 4.39 \\
\hline
\end{tabular}

Fig. 7 shows the resulting distributions of the work-order delay times for scenarios S1, S2 and S3.

Fig. 7 shows how the manufacturing system performance is significantly better in the scenarios $\mathrm{S} 2$ and $\mathrm{S} 3$ in comparison to scenario S1, with respect to the distribution of the work-order delay times. 
Comparing S3 to S2, the distributions of the workorder delay times are very similar, the number of work orders that are late is increased by $1.6 \%$, but in the case of the S3 scenario, the average work-order delay time is reduced by more than one day, the average waiting time of the work orders (before they are processed at work systems) is reduced by 6 hours, the work systems are more evenly loaded, and the average number of waiting work orders is decreased by $3.9 \%$.

The results indicate how the proposed cyberphysical approach to the management and control of a manufacturing system can facilitate the decision making at the level of management and control, and improve the manufacturing system's performance.

While the realization of the management and control system in the scenarios S1 and S2 is possible just by simple look-ups of the operators into the MES, the realization of the management and control system in the S3 scenario, due to the large-scale and dimensionality of the management and control problem, requires a more advanced approach that can be realized in the form of the proposed cyberphysical approach to the management and control of manufacturing systems. Nevertheless, the realization of the proposed approach would significantly facilitate the management and control process also for the cases of the scenarios S1 and S2.

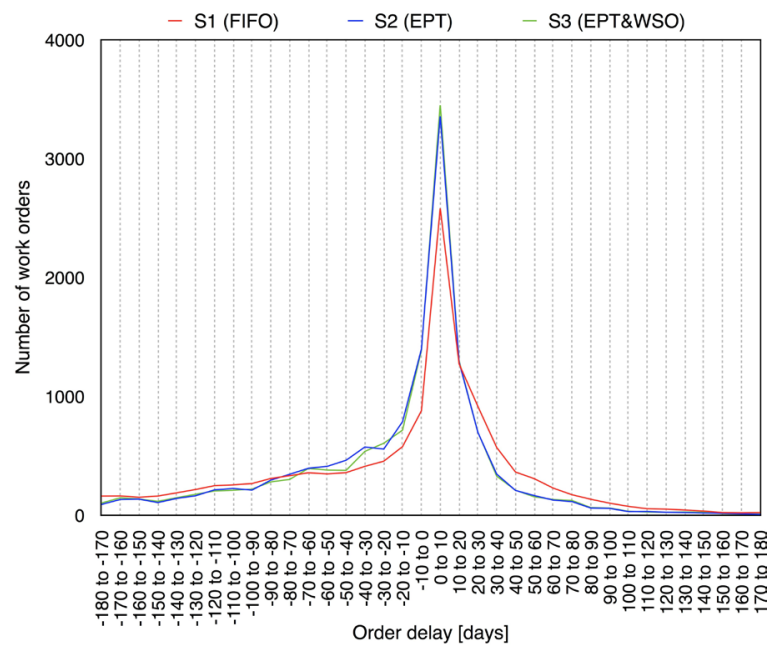

Fig. 7. Resulting distributions of the work-order delay time, adapted according to [28]

Focused on the proposed approach, a comparison of the simulation results indicates that introducing additional communications between the functions in the cyber system of the CPPS enables a better production performance with respect to the selected performance measures.
The case study was focused on the realization of the cybernated function of the scheduling and the new smart function of the self-organization in the concepts of the CPPS.

\section{CONCLUSION}

Cyber-physical systems and an advanced manufacturing technology open up new possibilities and potentials in the design, development, management and control of manufacturing systems. Today, manufacturing industry is faced with the technologies of a new industrial revolution - Industry 4.0 and new models for CPPSs. Accordingly, in this paper, a cyber-physical approach to the management and control of manufacturing systems is presented.

First, we structured a new CPPS model based on restructuring the traditional manufacturing structures in the spirit of CPS. Then, the cyber system of the CPPS was introduced and defined. The manufacturing structures in the cyber system enabled the development of a new method for the management and control of manufacturing systems.

The main advantage of a new model CPPS is that the elements of the cyber system of the CPPS enable the management and control of manufacturing systems in real time, through the realization of the digitalized and cybernated functions of the CPPS. The paper presents the approach of digitalization and cybernation of the PPC functions.

The presented approach is demonstrated on a case study based on real industrial data collected from an engineering-to-order company. The case study shows the feasibility and potential of the proposed approach.

Further research will be aimed at the implementation of the presented approach in a real industrial environment.

\section{ACKNOWLEDGEMENTS}

This work was partially supported by the Slovenian Research Agency, Grant No. P2-0270, by the Public Scholarship, Development, Disability and Maintenance Fund of the Republic of Slovenia, Grant No. 11011-79/2013, and by the Ministry of Higher Education, Science and Technology of the Republic of Slovenia, grant no. 1000-15-0510.

\section{REFERENCES}

[1] Bauernhansl T. (2013). Industry 4.0: Challenges and Opportunities for the Automation Industry. $7^{\text {th }}$ EFAC Assembly Technology Conference 2013, Davos. 
[2] Tao, F., Cheng, Y., Zhang, L., Nee, Y.C.A. (2017). Advanced manufacturing systems: socialization characteristics and trends. Journal of Intelligent Manufacturing, vol. 28, no. 5, p. 1079-1094, D0I:10.1007/s10845-015-1042-8.

[3] Lee, E.A. (2008). Cyber Physical Systems: Design Challenges. 11th IEEE International Symposium on Object and ComponentOriented Real-Time Distributed Computing, Orlando, p. 363369, D0I:10.1109/ ISORC.2008.25.

[4] Monostori, L. (2014). Cyber-physical production systems: Roots, expectations and R\&D challenges. Procedia CIRP, vol. 17, p. 9-13, D0I:10.1016/j.procir.2014.03.115.

[5] Wang, L., Törngren, M., Onori, M. (2015). Current status and advancement of cyber-physical systems in manufacturing. Journal of Manufacturing Systems, vol. 37, no. 2, p. 517-527, D0l:10.1016/j.jmsy. 2015.04.008.

[6] Liu, Q., Chen, J., Liao, Y., Mueller, E., Jentsch, D., Boerner, F., She, M. (2015). An application of horizontal and vertical integration in cyber-physical production systems. International Conference on Cyber-Enabled Distributed Computing and Knowledge Discovery, p. 110-113, Dol:10.1109/ Cyberc.2015.22.

[7] Monostori, L., Kádár, B., Bauernhansl, T., Kondoh, S., Kumara, S., Reinhart, G., Sauer, O., Schuh, G., Sinn, W., Ueda, K. (2016). Cyber-physical systems in manufacturing. CIRP Annals, vol. 65, no. 2, p. 621-641, D0l:10.1016/j.cirp.2016.06.005.

[8] Uhlemann, T.H.J., Lehmann, C., Steinhilper, R. (2017). The digital twin: Realizing the cyber-physical production system for industry 4.0. Procedia CIRP, vol. 61, p. 335-340, D0I:10.1016/j.procir.2016. 11.152.

[9] Cardin, 0. (2019). Classification of cyber-physical production systems applications: Proposition of an analysis framework. Computer in Industry, vol. 104, p. 11-21, D0I:10.1016/j. compind.2018.10.002.

[10] Alcácer, V., Cruz-Machado, V. (2019). Scanning the industry 4.0: A literature review on technologies for manufacturing systems. Engineering Science and Technology, an International Journal, vol. 22, no. 3, p. 899-919, D0l:10.1016/j.jestch.2019.01.006.

[11] Leitão, P., Rodrigues, N., Barbosa, J., Turrin, C., Pagani, A. (2015). Intelligent products: The grace experience. Control Engineering Practice, vol. 42, p. 95-105, Dol:10.1016/ j.conengprac.2015.05.001.

[12] Schuhmacher, J., Hummel, V. (2016). Decentralized control of logistic processes in cyber-physical production systems at the example of ESB Logistics Learning Factory. Procedia CIRP, vol. 54, p. 19-24, D0l:10.1016/j.procir.2016.04.095.

[13] Seitz, K.F., Nyhuis, P. (2015). Cyber-physical production systems combined with logistic models - a learning factory concept for an improved production planning and control. Procedia CIRP, vol. 32, p. 92-97, D0l:10.1016/j. procir.2015.02.220.

[14] Li, X., Gao, L., Zhang, C., Shao,. X., (2010). A review on integrated process planning and scheduling. International Journal of Manufacturing Research, vol. 5, no. 2, p. 161-180, DOI:10.1504/IJMR.2010.031630.

[15] Ouelhadj, D., Petrovic, S. (2009). A survey of dynamic scheduling in manufacturing systems. Journal of Scheduling, vol. 12, no. 417, D0l:10.1007/s10951-008-0090-8.
[16] Pfeiffer, A., Kádár, B., Monostori, L. (2007). Stabilityoriented evaluation of rescheduling strategies, by using simulation. Computers in Industry, vol. 58, no. 7, p. 630-643, D0I:10.1016/j.compind.2007.05.009.

[17] Cauvin, A.C.A., Ferrarini, A.F.A., Tranvouez, E.T.E. (2009). Disruption management in distributed enterprises: A multiagent modelling and simulation of cooperative recovery behaviours. International Journal of Production Economics, vol. 122, no. 1, p. 429-439, D0l:10.1016/j.ijpe.2009.06.014.

[18] Zhao, F., Wang, J., Wang, J., Jonrinaldi, J. (2012). A Dynamic Rescheduling Model with Multi-Agent System and Its Solution Method. Strojniški vestnik - Journal of Mechanical Engineering, vol. 58, no. 2, p. 81-92, Dol:10.5545/svjme.2011.029.

[19] Wang, X.L., Huang, H.B., Deng, S. (2012). List scheduling algorithm for static task with precedence constraints for cyberphysical systems. Acta Automatica Sinica, vol. 38, no. 11, p. 1870-1879, D0I:10.3724/SP.J.1004.2012.01870.

[20] Sluga, A., Butala, P., Peklenik, J. (2001). Self-organization in a distributed manufacturing system based on constraint logic programming. CIRP Annals, vol. 50, no. 1, p. 323-326, D0I:10.1016/S0007-8506(07) 62131-3.

[21] Schuh, G., Potente, T., Hauptvogel, A. (2014). Methodology for the evaluation of forecast reliability of production planning systems. Procedia CIRP, vol. 17, p. 469-474, D0l:10.1016/j. procir.2014.01.069.

[22] Zhang, Y., Qian, C., Lv, J., Liu, Y. (2017). Agent and cyberphysical system based self-organizing and self-adaptive intelligent shopfloor. IEEE Transactions on Industrial Informatics, vol. 13, no. 2, p. 737-747, Dol:10.1109/ TIl.2016.261889.

[23] Jiang, Z., Jin, Y., E, M., Li, Q. (2018). Distributed dynamic scheduling for cyber-physical production systems based on a multi-agent system. IEEE Access, vol. 6, p. 1855-1869, DOI:10.1109/ACCESS.2017.2780321.

[24] Barenji, A.V., Barenji, R.V., Roudi, D., Hashemipour, M. (2017). A dynamic multi-agent-based scheduling approach for SMEs. The International Journal of Advanced Manufacturing Technology, vol. 89, no. 9-12, p. 3123-3137, D0l:10.1007/ s00170-016-9299-4.

[25] Meissner, H., Aurich, J.C. (2019). Implications of cyber-physical production systems on integrated process planning and scheduling. Procedia Manufacturing, vol. 28, p. 167-173, DOI:10.1016/j.promfg.2018.12.027.

[26] Peklenik, J. (1995). Complexity in Manufacturing Systems. CIRP Journal of Manufacturing Systems, vol. 24, no. 1, p. 1725.

[27] Butala, P., Sluga, A. (2006). Autonomous work systems in manufacturing networks. CIRP Annals, vol. 55, no. 1, p. 521524, DOl:10.1016/S0007-8506(07)60473-9.

[28] Kozjek, D., Vrabič, R., Rihtaršič, B., Butala, P. (2018). Big data analytics for operations management in engineer-toorder manufacturing. Procedia CIRP, vol. 72, p. 209-214, DOl:10.1016/j.procir.2018.03.098. 